\title{
Wear and frictional mechanisms of copper-based bearing alloys
}

\author{
S. Equey*, A. Houriet, S. Mischler \\ Ecole Polytechnique Fédérale de Lausanne (EPFL), Tribology and Interfacial Chemistry Group, Station 12, CH-1015 Lausanne, Switzerland
}

\section{A R T I C L E I N F O}

\section{Article history:}

Received 13 October 2010

Received in revised form 29 March 2011

Accepted 30 March 2011

Available online 7 April 2011

\section{Keywords:}

Leaded bronze

Wear mechanisms

Third body

Microstructure

Roughness

\begin{abstract}
A B S T R A C T
The present study investigated the role of alloy microstructure and surface roughness on wear and friction behavior of leaded and unleaded tin bronzes. Ball-on-disk experiments were carried out under dry conditions with steel balls sliding against bronze disks. Scanning electron microscopy (SEM), energy dispersive electron microscopy (EDX), X-ray photoelectron spectroscopy (XPS) and Auger electron spectroscopy were performed to analyze the sliding tracks and the ball scars. The wear reducing effect of lead was associated to the formation of an oxidized lead rich layer. When no such film formed on the leaded bronze wear was more severe than in case of unleaded bronze. Nevertheless, the presence of lead in the alloy was a necessary but not sufficient condition to obtain a smeared layer and thus a lubricating effect of the leaded alloy. Two mechanistic hypotheses were formulated to explain the formation of the smeared layer.
\end{abstract}

(c) 2011 Elsevier B.V. All rights reserved.

\section{Introduction}

Leaded bronzes have been widely used as bulk material or as coating of steel pieces for applications as bearings, shafts or hydraulic pumps. Lead acts as an efficient solid lubricant in systems functioning under boundary or dry conditions. For environmental and legal reasons, efforts are being made to remove lead from bearing alloys. Numbers of materials are already proposed as alternative to leaded alloys, in particular metallic composites containing self-lubricant particles like graphite, $\mathrm{MoS}_{2}$ or PTFE [1-4]. Increasing the wear performances of alternative materials to leaded bronze requires a scientific understanding of the relevant mechanisms, and in particular of the relationship between materials microstructure and tribological behavior. However the present understanding of the mechanisms by which lead improves the tribological properties of alloys is limited.

Lead-base alloys, like babbit alloy, are used as soft coating for bearings. Upadhyaya et al. [5] compared the tribological properties of lead-base babbit alloys produced by casting and thermal spraying in relation with their microstructure. Due to the low melting point, lead was found smearing on the counterpart at an early stage of sliding process. This thin lubricating film efficiently protected the sliding parts against wear. Samples produced by thermal spraying showed a lower wear due to a smaller spacing between intermetallic particles. Dispersed lead particles are also used as solid lubricant in aluminum-based or copper-based alloys. Mohan et al. showed

\footnotetext{
* Corresponding author.

E-mail address: sebastien.equey@epfl.ch (S. Equey).
}

the effect of lead content in a stir-cast Al-Pb alloy [6]. An increase of the lead content led to a decrease of wear of up to $20 \mathrm{wt} \% \mathrm{~Pb}$. Higher $\mathrm{Pb}$ concentration increased the wear due to easier crack propagation and to the removal of thick layer of lead. The effect of lead content on $\mathrm{Cu}-\mathrm{Pb}$ alloys was studied by Pathak et al. [7]. Increasing the lead concentration up to $40 \mathrm{wt} \%$ led to a decrease in wear. The coefficient of friction also decreased up to $35 \mathrm{wt} \% \mathrm{~Pb}$ before increasing at higher lead content.

Pandey and Prasad studied the effect of applied pressure and sliding velocity on zinc-based and copper-based alloys [8]. The highest wear rate of the copper-based alloy was attributed to its microcracking tendency. The cracks were mostly present at low sliding speed and did not form at higher velocity due to the higher frictional heating.

Concerning leaded bronzes, the crucial role of third bodies in dry sliding has been previously observed with similar tribological conditions as in this study [9]. At low load, only small metal oxide particles were generated. Under higher contact pressure, lead-enriched larger flat debris were built up, decreasing the wear coefficient and the friction. Microstructure played an important role in the formation of the antifriction flat debris. Fewer but larger lead inclusions allowed building up the beneficial flakes under lower contact pressure.

In this study, the role of the alloy microstructure and of the surface roughness on dry wear and friction of leaded bronze is investigated with the aim to better identify critical mechanisms. A CuSn10Pb10, with two dendritic microstructures and a lead-free bronze, CuSn8, were studied. The sliding tracks and the ball scars were analyzed with scanning electron microscopy (SEM), energy dispersive electron microscopy (EDX), x-ray pho- 

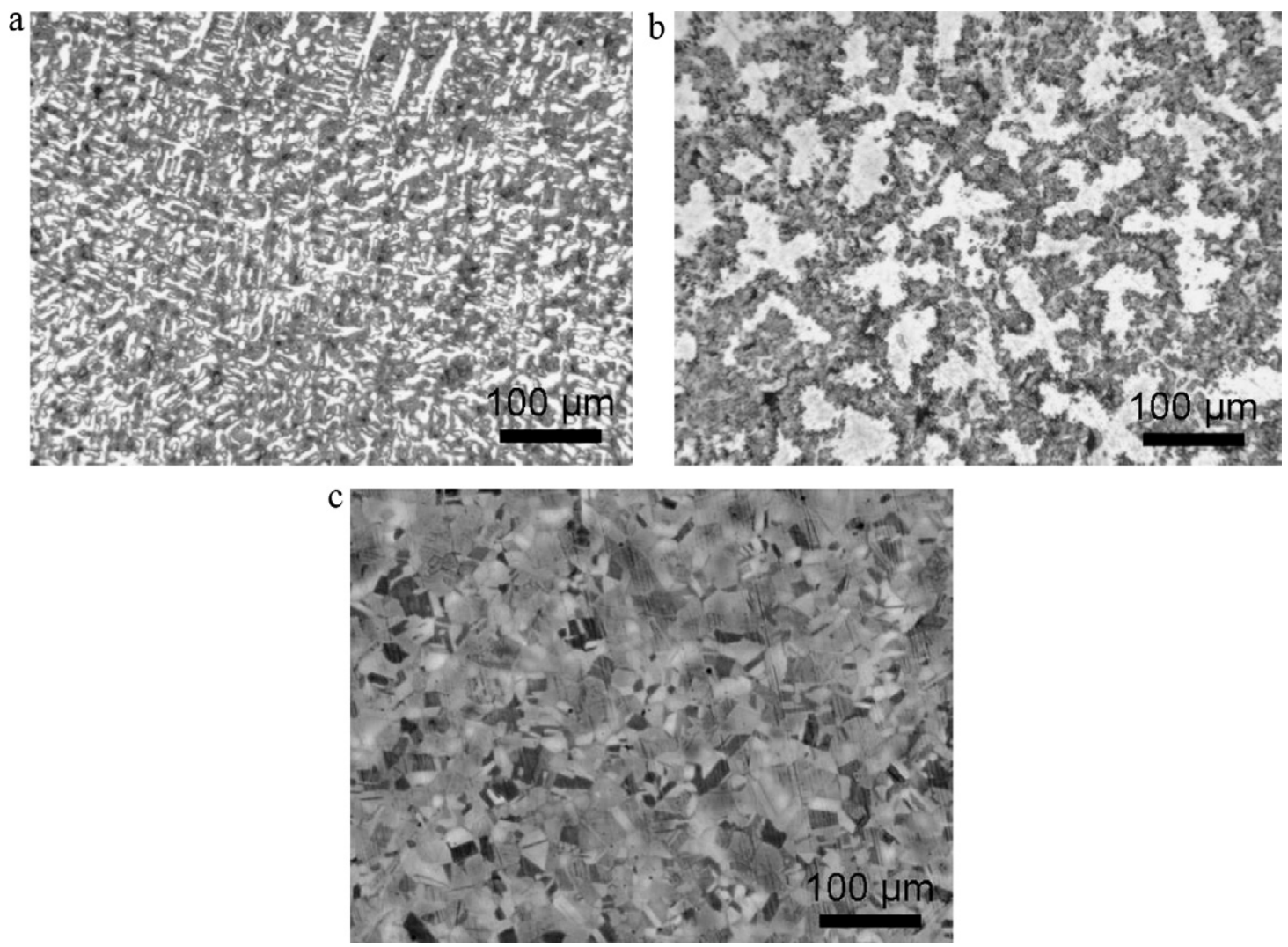

Fig. 1. Microstructures of a) fine dendrites CuSn10Pb10 (Br1), of b) coarse dendrites CuSn10Pb10 (Br2) and of c) CuSn8 (Br3).

Table 1

Microhardness, size of the lead particles and average roughness $R_{a}$ of the analyzed samples.

\begin{tabular}{|c|c|c|c|}
\hline & Fine dendrites $\mathrm{CuSn} 10 \mathrm{~Pb} 10(\mathrm{Br} 1)$ & Coarse dendrites CuSn10Pb10 (Br2) & CuSn8 (Br3) \\
\hline Microhardness & $94.4 \pm 6.6 \mathrm{HV}$ & $91.0 \pm 10.3 \mathrm{HV}$ & $70.7 \pm 0.7 \mathrm{HV}$ \\
\hline Size of $\mathrm{Pb}$ inclusions & $4.7 \pm 1.7 \mu \mathrm{m}$ & $28 \pm 12 \mu \mathrm{m}$ & - \\
\hline $\mathrm{R}_{\mathrm{a}}$ (as-machined) & $0.48 \pm 0.14 \mu \mathrm{m}$ & $1.6 \pm 0.4 \mu \mathrm{m}$ & $1.2 \pm 0.3 \mu \mathrm{m}$ \\
\hline $\mathrm{R}_{\mathrm{a}}$ (polished) & $0.09 \pm 0.02 \mu \mathrm{m}$ & $0.12 \pm 0.02 \mu \mathrm{m}$ & $0.07 \pm 0.02 \mu \mathrm{m}$ \\
\hline
\end{tabular}

toelectron spectroscopy (XPS) and Auger electron spectroscopy (AES).

\section{Experimental}

Materials: Ball-on-disk experiments were performed on three types of bronze: a CuSn10Pb10 alloy with a fine dendrites microstructure called later $\mathrm{Br} 1$, a CuSn10Pb10 alloy with a coarse dendrites microstructure called later $\mathrm{Br} 2$ and a lead-free bronze, $\mathrm{CuSn} 8$, called later $\mathrm{Br}$. The $\mathrm{Br} 1$ bronze corresponded to the asdelivered alloy and the $\mathrm{Br} 2$ alloy was obtained by casting the $\mathrm{Br} 1$ alloy followed by a heat treatment at $580^{\circ} \mathrm{C}$ during 1 hour. The asdelivered lead free $\mathrm{Br} 3$ alloy was annealed at $600^{\circ} \mathrm{C}$ during 2 hours.

Fig. 1 shows the microstructures of the investigated alloys as analyzed with optical microscopy. Alloy $\mathrm{Br} 1$ exhibits a fine dendritic structure (Fig. 1a) with uniformly dispersed small dark spots corresponding to the lead inclusions. The casted and heat treated alloy (Fig. 1b) presents a coarser dendritic structure with larger lead inclusions located mainly in inter-dendritic spaces. The structure of the lead free CuSn8 alloy (Fig. 1c) is homogeneous and single phased. Table 1 lists the Vickers micro-hardness (as measured on mirror polished samples with $2 \mathrm{~N}$ load applied during $15 \mathrm{~s}$ ) as well as the lead grain size and the average roughness $R_{a}$.

Additionally two surface finishing methods were used. A first series of samples was tested directly after machining with a met- alworking lathe and the second was polished with silicon carbide abrasive papers with grit sizes down to 4000 . Denominations of the different types of samples are detailed in Table 2. During polishing smearing of lead particles over the entire surface may happen. To check for this, AES analysis was carried out on polished surfaces. A lead signal could only be found in the lead inclusion but not on the bronze matrix. This indicates that no significant lead smearing occurred during polishing.

Tribological tests: A pin-on-disk tribometer previously described [10] was used for wear and friction tests. Rotating bronze disks were sliding against a stationary $100 \mathrm{Cr} 6$ ball (diameter of $6 \mathrm{~mm}$ ) at a sliding speed of $0.5 \mathrm{~m} / \mathrm{s}$ with a normal load of $2 \mathrm{~N}$ or $5 \mathrm{~N}$ during $500 \mathrm{~m}$. The radius of the disk wear track was $8 \mathrm{~mm}$. The most used normal load of $2 \mathrm{~N}$ corresponded to an average Hertzian contact

Table 2

Naming of the analyzed alloys with the corresponding surface finishing.

\begin{tabular}{lll}
\hline Name & Material & Surface finishing \\
\hline Br1-m & CuSn10Pb10 & As-machined \\
Br1-p & fine dendrites & Polished \\
Br2-m & CuSn10Pb10 & As-machined \\
Br2-p & coarse dendrites & Polished \\
Br3-m & CuSn8 & As-machined \\
Br3-p & & Polished \\
\hline
\end{tabular}


pressure of $383 \mathrm{MPa}$ for a contact diameter of $81.6 \mu \mathrm{m}$. The tests were performed under ambient conditions (temperature: $22 \pm 1{ }^{\circ} \mathrm{C}$ and $\mathrm{RH}: 40-50 \%$ ) and were repeated three times. A thermocouple was placed on the top of the steel ball (opposite to the contact) in order to detect frictional heating.

Wear volumes were measured by performing 8 line scans across the wear track using a UBM non-contact laser profilometer. The cross section area was extracted for the line scans by including the generally very small lateral ridges. The average wear track volume was determined for each sample by multiplying the average cross section area by the length of the track.

Characterization of worn surfaces: Surface imaging was performed with a SEM (FEI XLF30-FEG) and EDX analyses were performed with a $15 \mathrm{kV}$ acceleration voltage.

AES analysis was carried out with a Perkin-Elmer 660 scanning Auger spectrometer (Perkin Elmer, Waltham, MA, USA) using a $10 \mathrm{keV}$ electron-beam with a 5 or $10 \mathrm{nA}$ current (LaB6 source). Depth profiles were performed with a $2 \mathrm{keV}$ argon beam that corresponded to an etching speed of $3 \mathrm{~nm} / \mathrm{min}$ in $\mathrm{Ta}_{2} \mathrm{O}_{5}$.

XPS analyses of the wear track were performed with a Kratos Axis Ultra system (Kratos Analytical Ltd, Manchester, UK) using a monochromatic $\mathrm{Al} \mathrm{K \alpha}$ radiation as X-ray source. The diameter of the analyzed area was $400 \mu \mathrm{m}$. The pass energy and the step size were $80 \mathrm{eV}$ and $1 \mathrm{eV}$ for survey spectra and $40 \mathrm{eV}$ and $0.1 \mathrm{eV}$ for high-resolution spectra, respectively. The $\mathrm{C} 1 \mathrm{~s}$ peak was used as reference and was set at $285.0 \mathrm{eV}$. Measurements were performed without sputtering and after 1 minute Ar sputtering at $2 \mathrm{kV}$. XPS peaks were fitted using the CasaXPS software (Casa Software Ltd, Teignmouth, Devon, UK). Gaussian-Lorentzian curves were used as line shapes with an iterated Shirley background.

\section{Results}

Friction: The evolution of the friction during the experiments with polished surfaces is shown in Fig. 2. The Br3-p alloy showed the most reproducible behavior with a coefficient of friction stabilized around $0.66 \pm 0.01$. The Br1-p samples showed an increasing friction coefficient reaching in all cases a value around $0.62 \pm 0.04$ and Br2-p bronze showed a stable value of friction around $0.59 \pm 0.02$
Table 3

Tribological results of experiments repeated three times if not stated. (1) single measurement.

\begin{tabular}{lllll}
\hline & Material & Conditions & Friction coeff. & Wear $\left[\mathrm{mm}^{3} / \mathrm{m} \mathrm{N}\right]$ \\
\hline 1 & Br1-m & $2 \mathrm{~N} 0.5 \mathrm{~m} / \mathrm{s} 500 \mathrm{~m}$ & $0.30 \pm 0.08$ & $4.4 \cdot 10^{-4} \pm 0.7 \cdot 10^{-4}$ \\
2 & Br1-p & & $0.50 \pm 0.08$ & $4.5 \cdot 10^{-7} \pm 1.5 \cdot 10^{-6}$ \\
3 & Br2-m & & $0.45 \pm 0.15$ & $1.5 \cdot 10^{-5} \pm 1.6 \cdot 10^{-4}$ \\
4 & Br2-p & & $0.55 \pm 0.05$ & $2.7 \cdot 10^{-5} \pm 3.8 \cdot 10^{-5}$ \\
5 & Br3-m & & $0.64 \pm 0.06$ & $1.3 \cdot 10^{-4} \pm 0.2 \cdot 10^{-4}$ \\
6 & Br3-p & & $0.70 \pm 0.01$ & $1.7 \cdot 10^{-4} \pm 0.7 \cdot 10^{-4}$ \\
7 & Br2-p & $5 \mathrm{~N}, 0.5 \mathrm{~m} / \mathrm{s}, 500 \mathrm{~m}$ & $0.62(1)$ & $1.3 \cdot 10^{-5}(1)$ \\
& & & $0.21(1)$ & $3.6 \cdot 10^{-4}(1)$ \\
& & $0.23(1)$ & $1.8 \cdot 10^{-4}(1)$ \\
\hline
\end{tabular}

with the exception of one sample showing some discontinuities at the beginning and at the end of the tests. Similar trends in time evolution were observed with the machined surfaces although the absolute values of the coefficient of friction varied. The coefficients of friction averaged over the entire test duration are shown in Table 3. Independently on surface finishing the $\mathrm{Br} 1$ bronze showed the lowest coefficients of friction while the lead-free alloy showed the highest values. For all alloys, polishing increased the coefficient of friction

Wear: The wear track volumes measured on the bronze disks were converted into wear coefficient by dividing the wear volume by the applied load ( 2 or $5 \mathrm{~N}$ ) and the total sliding distance $(500 \mathrm{~m})$. The obtained data are listed in Table 3. Note the decrease by a factor of 1000 in wear rate induced by polishing on the $\mathrm{Br} 1$ bronze while surface finishing has no significant effect on wear of the other materials investigated here. The unleaded alloy exhibits more severe wear than the other bronzes with the exception of the Br1-m samples

Transferred bronze was generally found on the steel balls without any evidence of steel wear. The absence of steel damage is confirmed by the fact that steel debris particles could not be identified by AES, XPS or EDX on disks or balls.

Work hardening: Work hardening was determined by taking the difference between micro-hardness measured inside and outside the wear track and dividing it by the latter. Results are shown in
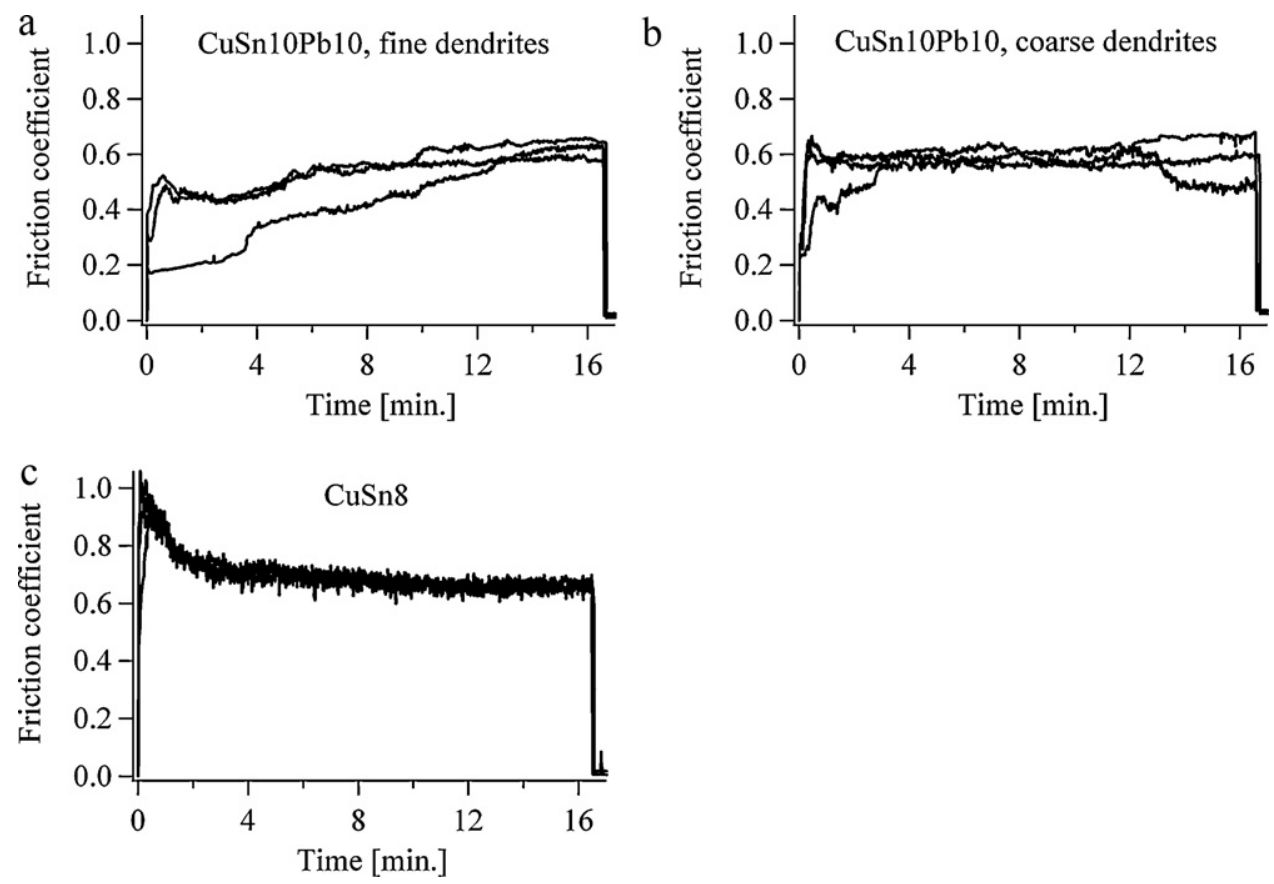

Fig. 2. Evolution of the friction coefficient with time for polished samples: a) Br1-p, b) Br2-p and c) Br3-p. 
Table 4

Vickers microhardness measured beside and inside the wear track.

\begin{tabular}{lllll}
\hline & Material & \multicolumn{2}{l}{ Vickers Microhardness } & Strain hardening [\%] \\
& & Out of track & On track & \\
\hline 1 & Br1-m & $166.2 \pm 9.0$ & $172.4 \pm 15.2$ & 3.7 \\
2 & Br1-p & $118.0 \pm 6.2$ & $136.2 \pm 7.1$ & 15.4 \\
3 & Br2-m & $181.2 \pm 35.7$ & $128.6 \pm 36.0$ & -29.1 \\
4 & Br2-p & $110.9 \pm 12.6$ & $128.8 \pm 9.3$ & 16.1 \\
5 & Br3-m & $150.4 \pm 19.1$ & $266.0 \pm 32.1$ & 76.9 \\
6 & Br3-p & $71.0 \pm 2.2$ & $171.1 \pm 14.8$ & 141.2 \\
\hline
\end{tabular}

Table 5

$\mathrm{Cu}: \mathrm{Sn}: \mathrm{Pb}$ ratios measured by EDX on particles and beside particles in the wear tracks of the leaded bronzes after $2 \mathrm{~N}$ load tribological tests.

\begin{tabular}{lll}
\hline & Cu: Sn: Pb ratio & \\
\hline Samples & On particles & Beside particles \\
Br1-m & $89: 7: 4$ & $91: 8: 1$ \\
Br1-p & $71: 5: 24$ & $88: 6: 6$ \\
Br2-m & $62: 6: 32$ & $93: 5: 2$ \\
Br2-p & $83: 7: 10$ & $91: 6: 3$ \\
\hline
\end{tabular}

Table 4. Small strain hardening was observed on the leaded bronzes while the unleaded one exhibited significant hardening. The sample Br2-m experienced softening instead of hardening. Note that the machined surface exhibits higher hardness outside the wear track probably because machining introduced some work hardening in the surface layer. During the progression of wear, the sliding surface may move below the surface layer affected by machining and thus experience softening. This could explain the decrease of hardness in the case of the Br2-m samples, while tribological hardening remains predominant in the case of the Br1-m samples

Bronze wear patterns: Fig. 3 shows the SEM images taken in the wear tracks on the bronze disks after the tests at $2 \mathrm{~N}$ for the different alloys and surface finishes. The unleaded surfaces present relatively large scratches with wedge formation. The worn surfaces on leaded bronzes are much smoother and in the case of $\mathrm{Br} 1$ bronze they are covered with particles. Such particles are clearly smeared in form of flakes on the $\mathrm{Br} 1-\mathrm{p}$ while on the machined $\mathrm{Br} 1$ samples they are more granular. The $\mathrm{Br} 2$ samples exhibit a surface layer apparently formed by smearing and compaction of particles. Smearing is more pronounced on the Br2-p samples as evidenced by the thin flakes observed in the centre/right of Fig. 3d and marked P1

EDX analyses were performed on the particles and beside the particles present in the wear track. Typical analysis spots are marked P1 and P2 on the SEM Images of Fig. 3. The obtained $\mathrm{Cu}: \mathrm{Sn}: \mathrm{Pb}$ atomic concentration ratios are shown in Table 5. The composition of the spots beside particles correspond well to the bulk alloy (Cu:Sn:Pb ratio of 91:6:3). On sample Br1-p a small increase in $\mathrm{Pb}$ concentration can be observed. The same hold for the particles found in Fig. 3a (Br1-m sample) while the other particles exhibit a marked enrichment in lead. However, EDX analysis gives values averaged over a sampling surface of $10 \mu \mathrm{m}^{2}$ and a sampling depth of approximately 2-4 $\mu \mathrm{m}$. Thus the presence of depth concentration gradients or lateral inhomogeneities of submicron size is not taken into account. To minimize such effects high depth resolution techniques, such as Auger electron spectroscopy combined with ion sputtering are necessary.

Auger depth profiling (Fig. 4) was carried out on such a flake as well as on a position not covered by a flake (such as the one marked P2 on Fig. 3d). The flake is covered by an oxide layer containing approximately 47 at.\% $\mathrm{Pb}, 37$ at.\% $\mathrm{O}$ and 16 at.\% $\mathrm{Cu}$ (Fig. 4 b). The thickness of this layer can be estimated at $15 \mathrm{~nm}$ after the conversion of sputter time into depth using the calibrated tantalum oxide sputter rate of $3 \mathrm{~nm} /$ minute. Around the flakes a film of similar composition but much thinner ( $3 \mathrm{~nm}$ ) covers the surface (Fig. 4a).Similar AES results were obtained with Br1-p samples with thick oxide film covering the flakes but not the surrounding areas.
XPS analyses were performed on non-contact regions and in the wear track on the four types of leaded bronze samples tested with a $2 \mathrm{~N}$ normal load. The large analyzed areas (diameter of $400 \mu \mathrm{m}$ ) gave average values of the species present on the samples, as it was not possible to distinguish flakes from bronze substrate. XPS surveys showed the presence of copper, tin, lead, oxygen and carbon. The analyses were performed before and after sputter cleaning to study any degradation due to the etching process. As no major alteration appeared, analyses after sputtering are shown. Fig. 5 shows the spectra of a Br1-p sample. Very similar spectra were recorded on the other samples. The copper $\mathrm{Cu} 2 \mathrm{p}_{3 / 2}$ signal showed a main peak at $932.4 \pm 0.2 \mathrm{eV}$ attributed to metallic copper or to $\mathrm{Cu}_{2} \mathrm{O}[11,12]$ and a minor contribution at $934.7 \pm 0.4 \mathrm{eV}$ attributed to copper +2 hydroxide $[11,13]$. The oxygen $01 \mathrm{~s}$ signal had two contributions at $530.1 \pm 0.3 \mathrm{eV}$ and $531.4 \pm 0.5 \mathrm{eV}$ attributed to metal oxides and to hydroxides or carbonates, respectively $[11,13,14]$. The main peak of tin $S n 3 d_{5 / 2}$ was detected at $486.3 \pm 0.4 \mathrm{eV}$ and was attributed to $\mathrm{Sn}(+2)$. A minor contribution was found at $485.1 \pm 0.4 \mathrm{eV}$ and was attributed to metallic tin [15]. The aliphatic carbon peak was used as reference and was set at $285.0 \mathrm{eV}$. Two other contributions were detected mostly on polished samples at $286.4 \pm 0.2 \mathrm{eV}$ and $288.8 \pm 0.2 \mathrm{eV}$ and were assigned to $\mathrm{C}-\mathrm{O}$ groups and to carbonates or carboxylic group, respectively [16,17]. The lead signal $\mathrm{Pb} 4 \mathrm{f}_{7 / 2}$ showed a main contribution at $183.3 \pm 0.3 \mathrm{eV}$ and a minor peak at $136.6 \pm 0.3 \mathrm{eV}$ corresponding to $\mathrm{Pb}(+2)$ and to metallic lead $[15,18-20]$, respectively. Signals of metal oxides $\mathrm{Cu}(+2), \mathrm{Sn}(+4)$ and $\mathrm{Pb}(+4)$ usually present at $933.7 \pm 0.3 \mathrm{eV}[11,12,21], 486.8 \pm 0.3 \mathrm{eV}$ $[15,21]$ and $137.5 \pm 0.3 \mathrm{eV}[15,21,22]$, respectively, were absent. No trace of iron was detected by XPS on any sample as measurement of the region of the $\mathrm{Fe} 2 \mathrm{p}_{3 / 2}$ signal was always performed.

Ball wear patterns: SEM/EDX was performed on the ball scars. Fig. 6 shows representative SEM images of ball scars for the four series of experiments with leaded bronzes and the two with unleaded bronze ( $2 \mathrm{~N}$ load). Large transfer was found on the balls sliding against unleaded bronze as well as against polished leaded bronze samples. Interestingly, sliding against as-machined samples does not yield any significant transfer. EDX analysis revealed that the transfer from the unleaded bronze $(\mathrm{Br} 3)$ had the same composition as the bulk bronze. The transfer film on the Br2-p samples was composed by lead only while the one formed by contact with the Br1-p disks was a mixture of lead (55 at. \%) and copper (45 at. \%) without any detectable Sn contribution

High-load wear test: Additionally unpublished results from a previous work studying the effect of load on the wear of leaded bronzes [9] are presented to confirm the critical role of the lead rich layer. The Br2-p alloy was characterized additionally at $5 \mathrm{~N}$ under otherwise identical conditions ( $500 \mathrm{~m}$ sliding distance, $0.5 \mathrm{~m} / \mathrm{s}$ ). The three independent tests carried out under this load yielded quite different results (Table 3 ). The first test showed a high friction $(\mathrm{CoF}=0.62)$ and a low wear rate $\left(1.3 \cdot 10^{-5} \mathrm{~mm}^{3} \mathrm{~m}^{-1} \mathrm{~N}^{-1}\right)$ similar to the one obtained at $2 \mathrm{~N}$. The two other tests exhibited low friction $(\mathrm{CoF}=0.21$ and 0.23$)$ and a high wear $\left(3.6 \cdot 10^{-4} \mathrm{~mm}^{3} \mathrm{~m}^{-1} \mathrm{~N}^{-1}\right.$ and $\left.1.8 \cdot 10^{-4} \mathrm{~mm}^{3} \mathrm{~m}^{-1} \mathrm{~N}^{-1}\right)$. SEM images of the corresponding disk wear tracks and of the counter ball are shown in the Fig. 7 a,b and 7 c,d, respectively.

The surface of the low wear specimen was covered by a smeared layer (Fig. 7a) which composition, as determined by EDX analysis, showed an atomic concentration ratio of 63:6:31. Comparing this value to the bulk composition (Cu:Sn:Pb ratio of $91: 6: 3$ ) clearly shows the massive lead enrichment of the smeared layer. The worn surface zones not covered by the smeared layer had the same EDX composition as the bulk alloy. Particles transferred from the bronze disk are visible on the counter ball. EDX analysis revealed that the transferred particles contain copper and lead in equivalent amounts while no tin signal can be detected. The composition and structure of the worn surface of the low wear specimen corre- 

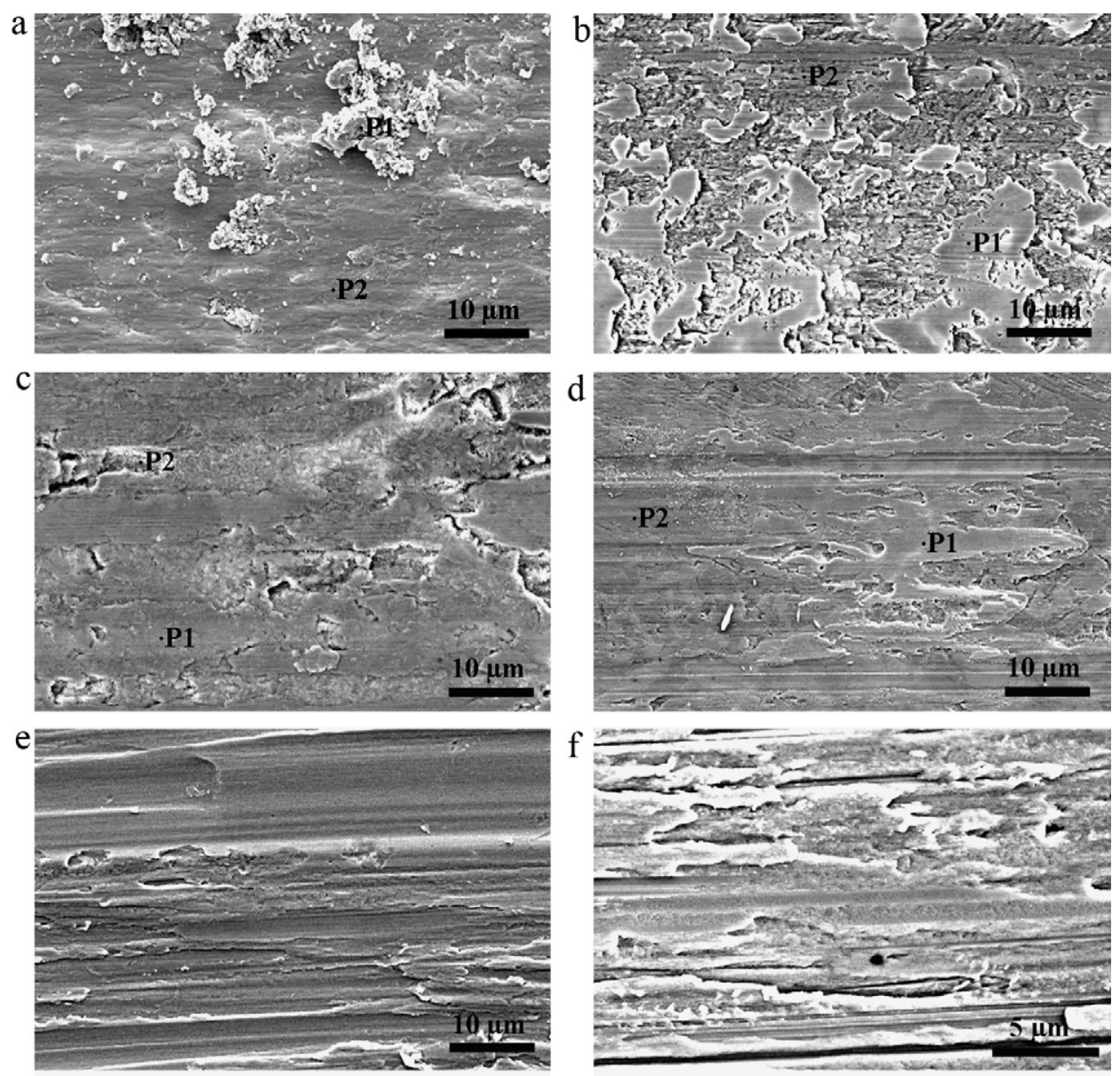

Fig. 3. Images of the disk wear track of a) Br1-m disk, b) Br1-p disk, c) Br2-m disk, d) Br2-p disk, e) Br3-m disk and f) Br3-p disk.

sponds well to the results observed at $2 \mathrm{~N}$ under otherwise similar conditions (Fig. 3d).

The high wear specimens exhibited different wear patterns. The bronze worn surface appears plastically deformed and cracked (Fig. 7b). The EDX analysis showed a $\mathrm{Cu}: \mathrm{Sn}: \mathrm{Pb}$ atomic concentration ratio of $89: 8: 3$, i.e. very closed to the bulk alloy. Thus no lead enrichment occurred here. Patches of bronze having the same composition as the bulk alloy adhered to the counter ball (Fig. $7 \mathrm{~d}$ ) but no lead-rich transfer layer could be detected.

The reason for the different behavior of the two kinds of samples is not understood at present. However, these results clearly show the correlation existing between presence of lead surface enrichment and wear.

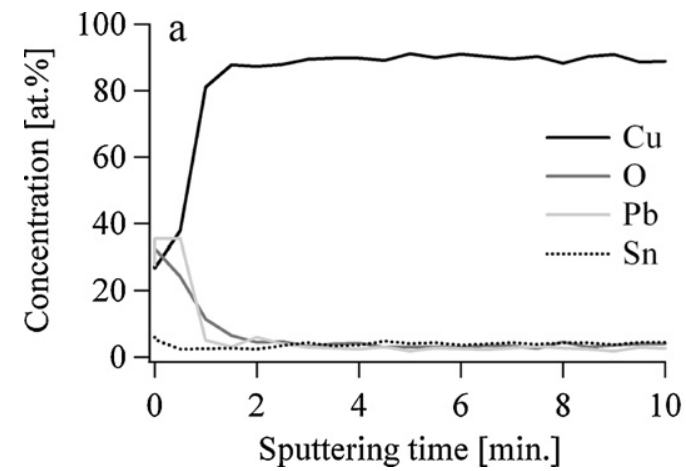

\section{Discussion}

\subsection{Wear mechanisms}

In the present experiments plastic flow characterizes the worn surfaces. This is not surprising since the contact pressure is high. Indeed the average Hertzian contact pressure under a $2 \mathrm{~N}$ normal load is $383 \mathrm{MPa}$, a significantly higher value than the yield strength of the CuSn10Pb10 alloy (110 MPa).

Leaded alloys do not necessarily lead to lower wear compared to the unleaded alloys. Indeed, the wear of the as machined, fine dendritic structure bronze $(\mathrm{Br}-1 \mathrm{~m})$ is much larger than the unleaded alloy. The other leaded bearing samples (Br1-p, Br2-m,

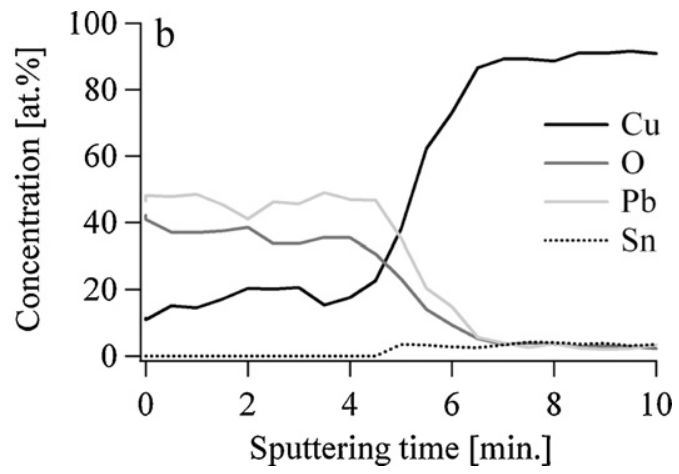

Fig. 4. Auger depth profiles measured in the wear track of a Br2-p disk. The profiles are measured a) out of flakes and b) on a smeared flake. 

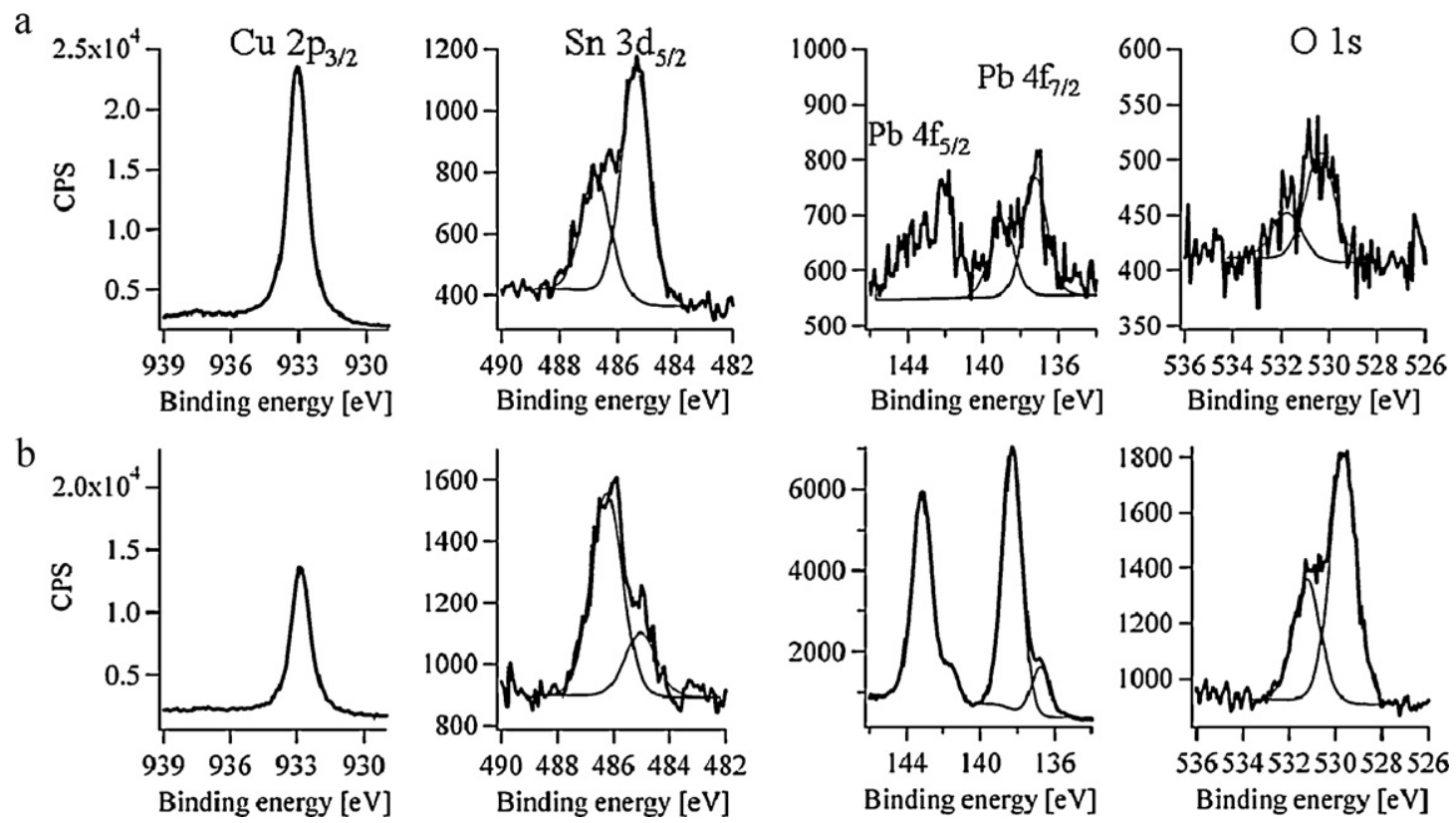

Fig. 5. Main XPS peaks measured a) in non-contact region and b) in the wear track in the case of a Br1-p sample. Surfaces were Ar-etched during 1 min. at 2 kV.
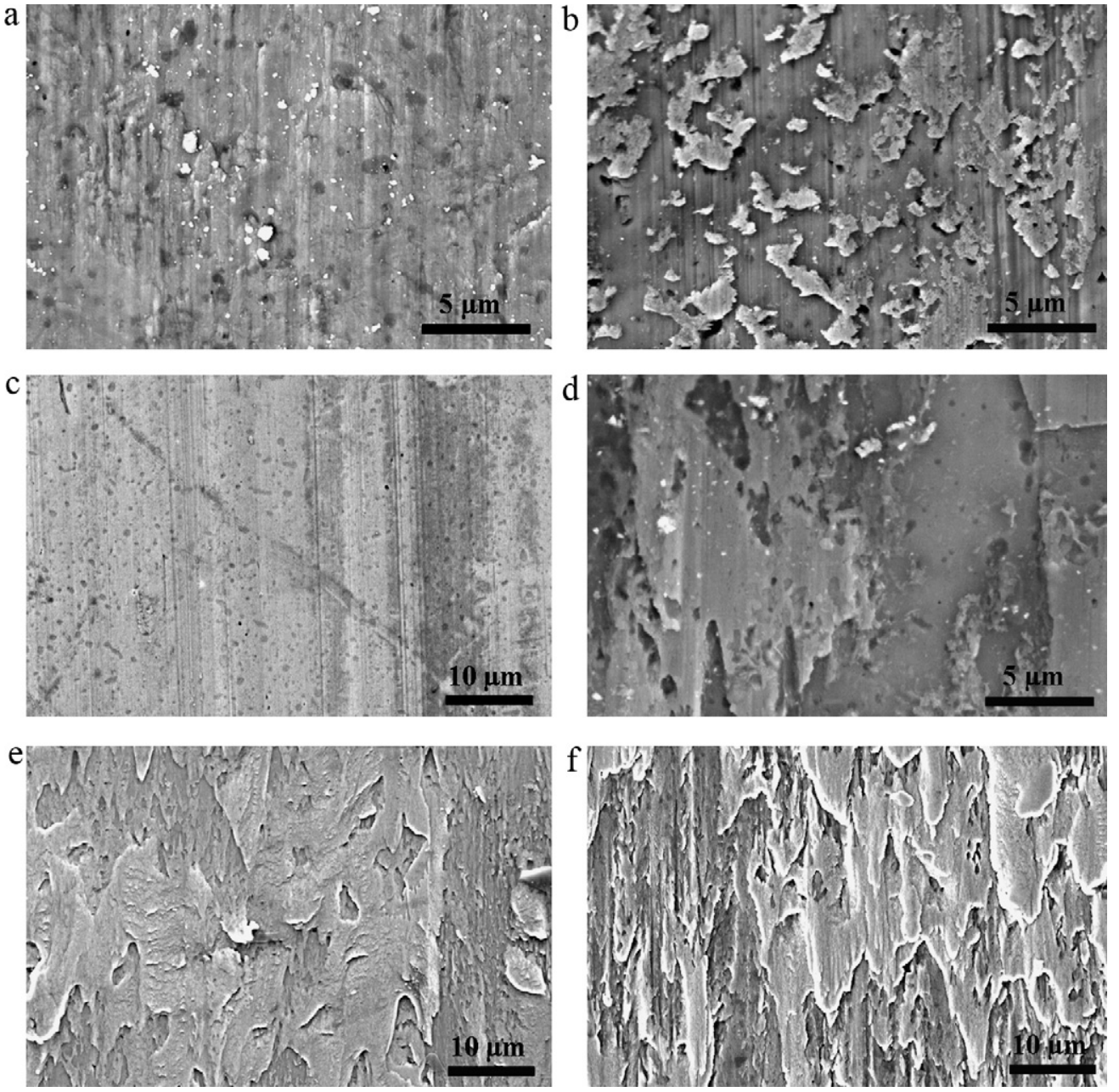

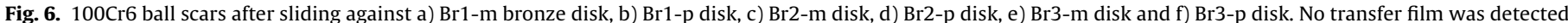
with EDX in the case a) and c), but transfer films were detected, containing 45 at. \% $\mathrm{Cu}$ and 55 at.\% Pb in the case b) and only lead in the case d). 

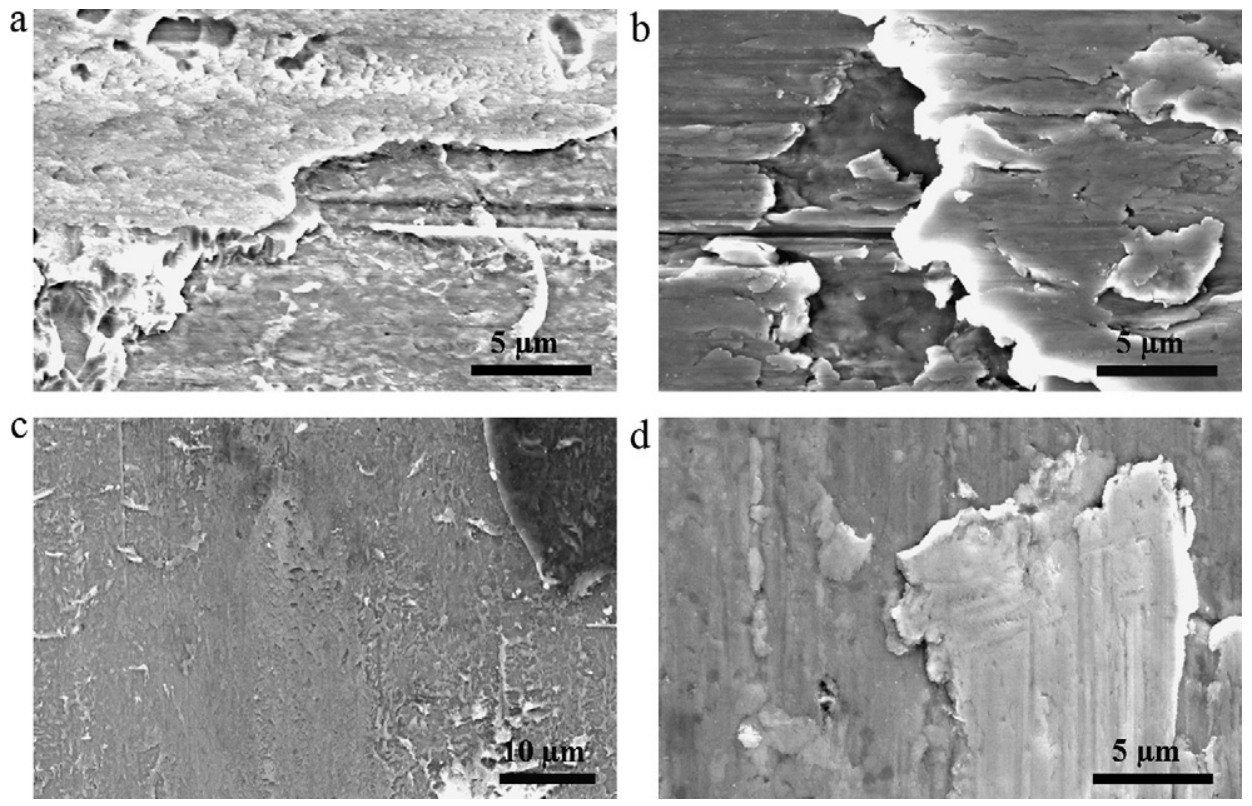

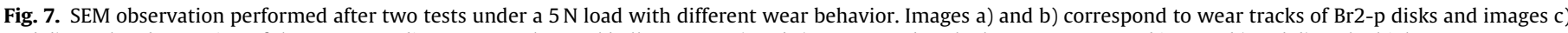
and d) are the observation of the corresponding scars on the steel balls. Images a) and c) correspond to the low-wear case and images b) and d) to the high-wear case.

Br2-p) exhibit lower wear coefficients than the unleaded alloy (Table 3).

The different wear behavior can be attributed to the formation of a lead enriched surface layer covering partially the bronze wear track and undergoing transfer to the counter piece. Such a smeared layer is indeed observed on the low wear leaded bronzes but not on the high wear $\mathrm{Br} 1-\mathrm{m}$ samples where granular third body particles accumulate in the contact. Moreover, the tests carried out at $5 \mathrm{~N}$ involving Br2-p samples confirm that the build up of a lead rich surface layer corresponds to a low wear situation.

Clearly, the presence of lead in the alloy is a necessary but not sufficient condition to obtain a smeared layer and thus a lubricating effect of the leaded alloy. Two hypotheses can be formulated to explain the formation of the smeared layer.

1) Lead inclusions may melt due to frictional heating. Lead would thus spread in the contact before further oxidizing and solidifying. This mechanism explains the appearance of the oxidized lead rich layer found by Auger profilometry (Fig. 4) and XPS. During rubbing other metallic elements can be incorporated in this layer as indicated by the $\mathrm{Cu}$ signal in the AES profiles. Lead oxide is a soft material and thus this layer likely acts as lubricant thus protecting against local pressure peaks leading to material damage and wear. This mechanism implies contact temperatures higher than the melting point of lead $\left(\mathrm{T}_{\mathrm{f}}=327.5^{\circ} \mathrm{C}\right)$. The contact temperature $T_{S}$ can be estimated from the temperature $T_{0}$ measured by the thermocouple positioned on the ball by using equation 1 [23]:

$T_{S}=T_{0}+\frac{\theta L_{1} \mu F_{N} v}{k_{1} A}$

Where $\theta$ is the fraction of frictional heat transferred through the ball (assumed here to be 0.5 ), $\mathrm{L}_{1}$ corresponds to the distance between the thermocouple and the effective contact (i.e. the diameter of the ball), $\mu$ is the coefficient of friction, $F_{N}$ is the normal load, $\mathrm{v}$ is the sliding velocity, $\mathrm{k}_{1}$ is the thermal conductivity of the $100 \mathrm{Cr} 6$ steel (here $45 \mathrm{~W} \mathrm{~m}^{-1} \mathrm{~K}^{-1}$ ) and $\mathrm{A}$ is the apparent contact area. The typical area $A$ in the present experiments is approximately $0.2 \mathrm{~mm}^{2}$ and the coefficient of friction is 0.5 . This corresponds to a theoretical temperature $T_{S}$ in the contact of approximately $210^{\circ} \mathrm{C}$. This shows the temperature significant increase in the contact and, considering the coarse approximations of this approach, the reaching of the melting point is possible. Further, the real area of contact is usually much smaller than the nominal one and thus the local temperature at asperity contacts can be significantly higher than the calculated value. Therefore in the present situation, melting of lead can likely occur in the contact. However, further evidence for frictional heating is needed to confirm this hypothesis.

2) Another mechanisms explaining the spreading of lead over the contact surface may rely to a selective wear of bronze phase. During sliding bronze and lead particles are detached from the base material. These particles may remain trapped in the contact for a certain time where they form a third body. The wear process is then determined by the behavior of the third body particles. Lead particles are soft and thus more prone to be smeared on the surface. Bronze particles cannot be smeared easily and thus their probability to be ejected from the contact is larger. Smaller bronze particles can remain in the contact and, under the shear stress acting in the contact, become smeared together with the lead particles. In this way lead rich flakes can be formed. These flakes can further oxidize due to frictional heating leading to the mixed copper-lead oxide found in Fig. 4 (AES profile).

The two mechanistic models allow analyzing the results obtained here. On polished samples molten lead can easily spread over the entire smooth surface and thus form timely the lead enriched layer that maintains low wear. On the machined samples roughness impedes spreading of molten lead and thus the build up of the lubricant layer at least until wear removes the asperities and mechanisms 1 can act. However, lead accumulation can proceed by selective wear (mechanisms 2 ) when bronze particles become preferentially ejected from the contact. The ejection of particles from a contact is a complex phenomenon that depends on several factors such as particle size, openness of the contact, system vibrations, kinematics. In the present case the two machined samples (Br1-m and Br2-m) presents different wear rates and mechanisms. Possibly, the finer microstructure of Br1-m samples leads to the formation of finer lead particles that can easily be ejected from the contact. Further, the facility for lead particles to be spread on the surface may also be affected by the particle size. This makes 


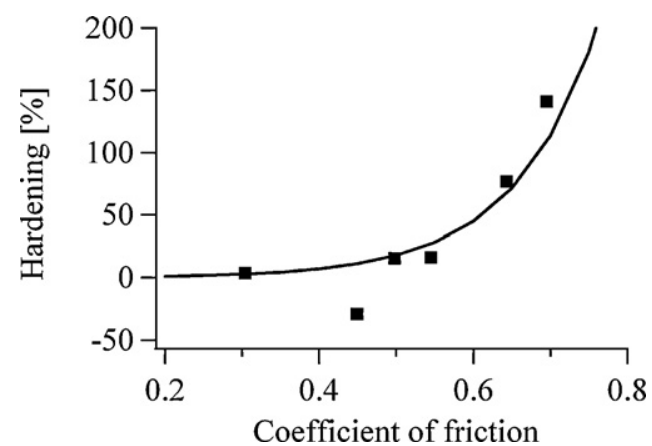

Fig. 8. Relation between the hardening due to friction and the coefficient of friction of leaded and unleaded alloys ( $2 \mathrm{~N}$ load).

that lead accumulation is faster on the Br2-m samples. This allows the formation of the lead enriched lubricant layer (as evidenced by EDX) and the wear mechanisms become similar to the one observed on polished surfaces (spreading of material).

Clearly, the mechanistic hypotheses mentioned above are at present highly speculative and need to be substantiated by a better characterization of powder rheology and thermal effects in contacts. Nevertheless they clearly show that the effect of lead, and thus of similar behaving solid lubricant alloying elements, is not simple and how it could be affected by thermal, micro structural and surface topography factors as well as debris particles behavior.

\subsection{Work hardening and friction}

The coefficient of friction values from Table 3 where plotted in Fig. 8 versus the corresponding values characterizing work hardening (Table 4) to evaluate any possible correlation between the two factors. Interestingly work hardening was found to increase exponentially with the raise of the friction. The hardening of the bronze matrix was in direct relation with the friction independently from the lead content of the alloys. For example, the Br1-m samples showed the lowest coefficient of friction for the second lowest work hardening even without lead enrichment. Such a behavior is somehow expected due to the large plastic flow and the associated energy dissipation of the bronze observed during rubbing. Note that no clear correlation is found between work hardening or friction and wear (Tables 3 and 4). Indeed the samples $\mathrm{Br} 1-\mathrm{m}$ exhibit the lowest friction but also the highest wear. The present results suggest that friction results essentially from subsurface deformation that not necessarily leads to the detachment of wear debris. Further, debris detached from the deformed bronze may remain trapped within the contact and thus become smeared on the contact surface. In this way they would not contribute directly to material loss and wear.

\section{Conclusion}

The present investigation of the dry sliding behavior of a leaded CuSn10Pb10 bronze loaded against a steel ball has lead to following conclusions:

- Energy dissipation is essentially controlled by the plastic deformation of the bronze subsurface as evidenced by the exponential dependence of work hardening on friction observed here.

- The wear reducing effect of lead is associated to the formation of an oxidized lead rich layer of approximately $15 \mathrm{~nm}$ thickness covering the wear track. When no such film forms on the leaded bronze wear is more severe with respect to unleaded bronze.

- The formation of the lead rich layer and the wear behavior of the bronze depend on the combined effect of microstructure and surface roughness.

- Two mechanistic models describing the build up process of the lead rich layer were proposed based on lead melting due to frictional heating and on a third body approach.

\section{Acknowledgements}

This work was financially supported by the Swiss Innovation Promotion Agency (CTI). The authors thank N. Xanthopoulos for surface analysis. The authors are grateful to Kugler Bimétal SA (Le Lignon/Geneva, Switzerland) for providing the bronze samples analyzed in this study and for fruitful discussions.

\section{References}

[1] M.F. Cardinal, et al., Surf. Coat. Tech 204 (1-2) (2009) 85-90.

[2] M. Kestursatya, J.K. Kim, P.K. Rohatgi, Metall. Mater. Trans. A 32 (8) (2001) 2115-2125.

[3] J. Kovacik, et al., Wear 265 (3-4) (2008) 417-421.

[4] T. Li, et al., J. Appl. Polym. Sci 80 (13) (2001) 2394-2399.

[5] A. Upadhyaya, N.S. Mishra, S.N. Ojha, J. Mater. Sci 32 (12) (1997) 3227-3235.

[6] S. Mohan, V. Agarwala, S. Ray, Wear 157 (1) (1992) 9-17.

[7] J.P. Pathak, S.N. Tiwari, Wear 155 (1) (1992) 37-47.

[8] J.P. Pandey, B.K. Prasad, Metall. Mater. Trans. A 29 (4) (1998) 1245-1255.

[9] S. Equey, P. Bosc and S. Mischler, Proceedings of the 14th Nordic Symposium on Tribology -Nordtrib 2010.

[10] E. Sauger, JFTC 1998, (1998) p. 167-178.

[11] N.S. McIntyre, M.G. Cook, Anal. Chem 47 (13) (1975) 2208-2213.

[12] S. Poulston, et al., Surf. Interface Anal 24 (12) (1996) 811-820.

[13] E. Cano, et al., J. Electrochem. Soc 148 (1) (2001) E26-E30.

[14] J.K. Heuer, J.F. Stubbins, Corros. Sci 41 (7) (1999) 1231-1243.

[15] J.A. Taylor, G.M. Lancaster, J.W. Rabalais, J. Electron Spectrosc 13 (3) (1978) 435-444.

[16] D.J. Balazs, et al., Biomaterials 25 (11) (2004) 2139-2151.

[17] G. Beamson and D. Briggs, High Resolution XPS of Organic Polymers, John Wiley \& Son Ltd ed. (1992)

[18] S. Rondon, P.M.A. Sherwood, Surface Sci. Spectra 5 (2) (1998) 83-89.

[19] S. Rondon, P.M.A. Sherwood, Surface Sci. Spectra 5 (2) (1998) 97-103.

[20] J.M. Thomas, M.J. Tricker, J. Chem. Soc. Farad. T. 271 (1975) 329-336.

[21] J.F. Moulder et al. Handbook of X-ray Photoelectron Spectroscopy (1995) Physical Electronics, Inc.

[22] S. Rondon, P.M.A. Sherwood, Surface Sci. Spectra 5 (2) (1998) 104-110.

[23] D. Landolt, Corrosion and Surface Chemistry of Metals (2006), CRC Press, Taylor \& Francis Group. 